\title{
Bias in Homeopathy: Technical Note
}

\section{Salvatore Chirumbolo}

Department of Medicine, University of Verona, LURM Est Policlinico GB Rossi, Piazzale Al Scuro 10, 37134 Verona, ITALY

Email: salvatore.chirumbolo@univr.it

\begin{abstract}
Homeopathy is fundamentally based on the assumption that a biological activity is borne by a chemical system made by a molecular solute within a solvent that is diluted and mechanically stressed an undefined number of times and then reaches a zero point where molecules disappear and the solvent is the only chemical species being left. With the exception of an author who recently stated "We have been working in this field for over 20 years [35], and are thus perfectly aware of the issues related to the "plausibility" of high-dilution pharmacology, particularly when using dilutions beyond Avogadro's constant", yet no evidence was reported to date about the real nature of homeopathic high dilutions.
\end{abstract}

Keywords: homeopathy; bias; dilutions; chemical system; water

\begin{tabular}{ll}
\hline $\mathbf{6 0} / \mathbf{2 0 1 7}$ & Source of Support: Nil, No Conflict of Interest: Declared \\
\hline This article is is licensed under a Creative Commons Attribution-NonCommercial 4.0 International License. \\
$\begin{array}{l}\text { Attribution-NonCommercial (CC BY-NC) license lets others remix, tweak, and build upon work non-commercially, and although the new works must also } \\
\text { acknowledge \& be non-commercial. }\end{array}$
\end{tabular}

\section{Presentation}

Homeopathy is fundamentally based on the assumption that a biological activity is borne by a chemical system made by a molecular solute within a solvent that is diluted and mechanically stressed an undefined number of times and then reaches a zero point where molecules disappear and the solvent is the only chemical species being left (Bellavite et al., 2014a; Bellavite et al., 2014b). This simplistic view should retain the belief that homeopathy is based on a fake, as no solvent possesses the extreme variability of molecular masses acting on any biological system. The naïve and simplistic approach to calculate the residual mass still existing in the bulk solvent after a homeopathic dilution is founded on a Dalton's derived model where molecules are considered as having the same gas-like behaviour and atomic mass unit. A gas-like system is fundamentally made by particles within water, e.g. molecules, which exhibit a gas-like behaviour and do not heterogeneously interact with solvent aside from following statistics and thermodynamics of the moving molecules by chance. Homeopaths consider exclusively a gas-like system during their calculations and never mind the effect of solvents on dilutions (Bellavite et al., 2015; Magnani et al., 2010; Bellavite et al., 2011). Solvents, quite exclusively represented by water, would show their major role only when dilutions are theoretically deprived of any active principles, never before (Vallance, 1998; Milgrom, 2006; Bellavite et al., 2011). According to this approach, homeopaths calculate that a theoretical concentration made by 1.0 moles/L of a defined compound A undergoing twelve centesimal dilution steps, reaches the zero log point of the dilution function $f(x)$ corresponding to 1 molecule/liter or a theoretical concentration of 1.67 yoctomoles/liter (1.67 yM or $\left.1.67 \times 10^{-24} \mathrm{M}\right)$. According to this thesis, a $13 \mathrm{cH}$ should not contain any molecule but the sole solvent. This elementary, quite childish approach, is based on the linear function derived from the log transformation of $\left[y=a-b^{x}\right]$, where $y$ is the final concentration of the compound A following a dilution, $\mathbf{a}$ is the concentration of $\mathrm{A}$ at the beginning of the dilution process (time 0 ), $\mathbf{b}$ is the dilution factor and $x$ is the series or step of the dilution process. This equation does not take into account the effect of solvent and may be rewritten as $\left[y^{\prime}=\mathrm{c}-\mathrm{d}^{x}\right]$, where $y^{\prime}$ is the amount of the A mass of $\mathrm{A}$ at the $x$ dilution step, $\mathbf{c}$ is the starting mass of $\mathrm{A}, \mathbf{d}$ is the mass subtracted in a centesimal dilution $\left(=10^{2}\right)$ and $x$ the dilution step. The $\log$ transformation of this equation generates an $f(x)$ represented by a log/lin linear curve: $[y=$ 
$\mathbf{c}-\mathbf{d} x]$, considering $\mathbf{c}$ and $\mathbf{d}$ as constants. Therefore, the linear approach of a homeopathic dilution is similar to the serial homogeeous subtraction of a solid mass from a container. The model is based on a Dalton's simplistic vision of chemical masses, dated back to the 1814, when Avogadro established his very famous principle. In this model the Avogadro's constant is related to the atomic mass unit ( $\mathrm{amu}$ ), indicated with $u$ and defined as the unitary mass number or the $12^{\text {th }}$ part of carbon ${ }^{12} \mathrm{C}$ atomic mass and in this sense the Avogadro's number of these elementary units corresponds to $1 \mathrm{~g}$, i.e. $1.00 \mathrm{~g}=\mathrm{N}_{\mathrm{A} u} \approx 6.022 \times 10^{23} u$ or, the same, $1 u \approx 1.660538921 \times 10^{-27} \mathrm{Kg}$. The tenet of homeopathic high dilutions indirectly considers any molecule as a simple particle with this unitary dimension. When authors measure some presumptive active principle, i.e. gelsemine from Gelsemium sempervirens, their consideration although referring to this approach might give birth to gross biases. A starting concentration of gelsemine as low as $6.5 \times 10^{-4} \mathrm{M}$ corresponds approximately to $1.22172024 \times 10^{18} u \approx 1.22 \times 10^{18} u \approx 10^{18} u$, if a gram of gelsemine is calculated as $1.8795696 \times 10^{21} u$. Homeopaths should be honest in considering these issues when naively calculate their dilutions, a circumstance that should suggest the zero log intercept ( 1 molecule) within the $9 \mathrm{cH}$ range, in this specific example. Yet, this approach cannot fulfil completely the complexity of a solution made by a huge variability of organic molecules, as in the case of a raw plant extract. Usually, when herbal extracts are considered, researchers endeavoured to demonstrate the scientific ground of homeopathy, explain any presumptive effect related to a high dilution with the pharmacological activity of the molecule that has theoretically disappeared at that dilution (Magnani et al., 2014; Marzotto et al., 2014; Olioso et al., 2014). Obviously this is a conceptual absurdum in the linear approach. Actually, the behaviour of a complex mixture of different phenolic and organic compounds in a water/ethanol solvent is highly complex and unpredictable and might change dramatically any consideration about how reaching the zero point (Chirumbolo, 2011).. Researchers should evaluate the concentration of the supposed active principle at any centesimal dilution performed throughout the whole process, rather than founding their conclusions on previous non revised quantitative calculations (Marzotto et al., 2014; Olioso et al., 2014). The approach based on a Daltonian simplistic view of high dilutions may generate gross biases in the real comprehension of the nature of high dilutions. The linear model, arranged to achieve the Avogadro-Loschmidt's threshold by simple algebraic calculations on the serially distributed dilutions, should reach theoretically this threshold only when: a) the molecule can be perfectly fitted to Daltonian's amu in the water/ethanol solvated form; b) the molecule is perfectly solvated into the bulk solvent, homogeneously dispersed without nano-heterogeneous niches, molecular abducts, colloids or nanoaggregates; c) water is never nano-heterogeneously structured when in its liquid thermodynamic state; d) the molecule does not interact with other molecules, biological surfaces, nanobubbles and the liquid/air compartment (surface); e) the molecule does not interact with the wall of the glass container; f) the molecule does not have any asymmetric interaction with ethanol in the solvent water/ethanol; g) physical factors, such as temperature, storage, air pressure, glass, nanobubbles and so on do not affect the dilution process; h) handling and process, such as withdrawal with laboratory tips, do not affect the dilution process; i) the carry over component coming from the thermodynamic equilibrium of different regions (interface liquid/gas, interface liquid/container walls, interface biological structures or suspended, colloidal nano-aggegates and bulk solvent, nano-heterogeneous niches) is negligible respect to bulk liquid. These conditions are almost never fulfilled in the real world. Homeopaths naively hypothesize that any molecule coming from a hydroalcoholic raw extract from plants enter the water/ethanol solvent and form a perfect solution where any molecule is homogeneously distributed in the bulk liquid. Moreover, more frequently operators pick up molecules by withdrawing a little aliquot of solution very close to the interface liquid/gas of the same solution, where molecules may have a relationship with solvents quite different respect to the bulk liquid. Some author has reported that even very high diluted chemical systems may yet have matter (mass particles) of the previous concentration prevalently at the interface liquid/gas (Chikramane et al., 2010; Chikramane et al., 2012). This evidence makes puzzling any further issue concerning the chemical nature of a high dilution into water. Actually, the solubility profile of different biomolecules extracted from plant depends on the ratio water/ethanol and more precisely on the chemical feature of molecules, their hydrophobic/ hydrophilic characteristics, the molar mass of ethanol, the nano-heterogeneous behaviour of stressed (perturbed) water, the presence of bio-organic surfaces, the chemical composition of the container walls. Therefore, plant-derived molecules in a solution made by water and ethanol organized their place within the chemical system in a more complex way and at any dilution step a thermodynamic equilibrium, according to the Langmuir adsorption isotherm, exists between the surface of the container walls and the bulk liquid, the interface liquid/gas and the bulk liquid, the different niches made by nano-colloid aggregates and solutes by changing the molar mass of ethanol in water and bulk liquid, the dispersed particles and nanosized systems such as nanobubbles. This circumstance may change dramatically the exact concentration of a defined molecule in a centesimal high dilution, where a $30 \mathrm{cH}$ may be really a $17 \mathrm{cH}$ or a $9 \mathrm{cH}$, depending on the type of dilution made (Chatterje, 2015). Therefore, some homeopathic remedies may work because of an incorrect evaluation of their concentration, generating concern about their possible adverse effects (Csupor et al., 2013; Chirumbolo, 2013; Chirumbolo, 2014). Therefore, when evaluating the amount of molecules entering a defined dilution, the operators should take into account: a) the amount in the bulk liquid; b) the amount in equilibrium from 
walls to the bulk liquid; c) the amount in equilibrium between solutes and nanoclusters or nanoaggregates (nanocolloids) in a nanostructured water; $d$ ) the amount at the interface liquid/gas; e) the amount in equilibrium between different solvents and their different molar masses during dilution; $f$ ) the carryover effect of withdrawing tips. The linear reduction of a) is biased by the many factor here indicated, widely described as factors present in a complex solution, and while increasing the dilution, steps factors b) to f) should enhance their effect on the final calculation of the concentration of the compound $\mathrm{A}$ in the dilution. This means that, with some approximation, the linear function $f(x)$ in the equation $\left[y^{\prime}=c-d^{x}\right]$ is most probably valid at the beginning of dilution, when the concentration of the compound $\mathrm{A}$ is very high, the leakage from walls is negligible, the distribution at the interface liquid/gas is in a dynamical equilibrium with the bulk solvent and does not change this latter, the occurrence of solvent-derived nanosized species is low and the plastic tip has a very low carry over ability. However, the linear component expressed by $[y=c-d x]$ in a $\log /$ lin transform is going to be overwhelmed by the increase of the non bulk-components while increasing the dilution and the equation should change as $\left[y^{\prime}=\mathrm{c}^{-\mathrm{d}^{-x}}\right]$ and then (log transf) as the equation $[y=\mathrm{e}-\mathrm{f} / x]$, which represents a hyperbole of the $[y=\mathrm{c}-\mathrm{d} x]$ if the concentration of the compound A depends on the non bulk components that increase with ongoing the dilution steps. The effect of carry over of very few molecules between the tip and the interface liquid/gas, where with increasing dilutions increase nanobubbles and nanosized water structures (Roy et al., 2008) and the possible activity of nanostructures (Demangeat, 2015), may represent important factors that hamper dilutions to reach the zero intercept at $1.67 \mathrm{yM}$ with the supposed linear approach and probably high dilutions are asynptotes and perhaps they never reach the zero (Chikramane et al, 2010).

However, strictly from a pharmacological point of view, if resting molecules in very high diluted chemical systems are below $1.0 \mathrm{aM}\left(10^{-18} \mathrm{M}\right)$, they cannot interact by chance with biological receptors and signaling molecules or enzymes, leading to a sustained, reproducible and reliable biological effect, as 1.0 amole is the lowest limit permitted in the mass action law (Gurevich et al., 2003). Therefore, in a high dilution, homeopaths cannot be sure, unless they evaluate how the concentration of the compound A is fading away, of how much compound A is present at any step. The effect of solvent is yet to be elucidate. According to Elia and coworkers, liquid water undergoing serial dilutions and mechanical stress, filtration or Nafion treatment behaves as a dissipative structure and is able to aggreagate at standard pressure and room temperature (Elia et al., 2007; Elia et al., 2013; Elia et al., 2013b; Elia et al., 2013c; Elia et al., 2014; Elia et al., 2015). This evidence should suggest that water, which exhibits the ability to form macroscopic aggreagates, bears an informative variability. In an attempt to elucidate this conundrum, we might speculate that the variability attributed to the nanoheterogeneity and dissipative property of water could bear an information able to be translated by cell in a defined function. Although some thesis was recently forwarded (Ynnon, Elia, 2013; Czerlinski and Ypma, 2010), water structures were never demonstrated to bear a bioactive property. Even when supposed water aggregates were investigated in a biological system the effect was scarcely reproducible, contrarily to the evidence that these structures may even be macroscopic (Brizzi et al., 2011). Homeopaths are therefore convinced that water is able to bear a bio-active information. Whether water structures are real or not, although they are not visible in any diluted solutions and do not interfere with light adsorption, they cannot be involved in any information because there is neither hypothesis nor evidence able to explain why water, which is the same in any dilution aside from its original source, may elicit a biomolecular activity without any biomolecule. Furthermore, no researcher has ever demonstrated to date that these presumptive aggregates may hide molecules, which disappear at any analytical chemistry assay but might be released in a biological target.

These are all speculations, of course. The existence of water structures should give a high impact on the reproducibility of randomized controilled trials with homeopathic remedies, just because these structures are easily to form and with micro- or macroforms amounts, able to trigger a cell response likewise a massive molecule. Yet, only dilutions still containing molecules were reported as active in blinded vs placebo randomized controlled trials (RCTs), while other formulas gave negative evidence and high diluted preparations showed less reproducible results but only in some report about mental and somatoform syndromes, such as irritable bowel syndrome (IBS) and fibromyalgias, where placebo should play a major role (Peckam et al., 2013; Adler et al., 2013; Macías-Cortés Edel et al., 2013; Zanasi et al., 2014; Pérol et al., 2012; Bell et al., 2004; Fisher et al., 1989). With the exception of an author who recently stated We have been working in this field for over 20 years, and are thus perfectly aware of the issues related to the "plausibility" of high-dilution pharmacology, particularly when using dilutions beyond Avogadro's constant (Bellavite et al., 2011), yet no evidence was reported to date about the real nature of homeopathic high dilutions.

\section{REFERENCES}

Adler UC, Krüger S, Teut M, Lüdtke R, Schützler L, Martins F, Willich SN, Linde K, Witt CM. Homeopathy for depression: a randomized, partially double-blind, placebo-controlled, four-armed study (DEP-HOM). PLoS One. 2013 Sep 23;8(9):e74537

Bell IR, Lewis DA 2nd, Brooks AJ, Schwartz GE, Lewis SE, Walsh BT, Baldwin CM. Improved clinical status in fibromyalgia patients treated with individualized homeopathic remedies versus placebo. Rheumatology (Oxford). 2004 May;43(5):577-82

Bellavite P, Magnani P, Conforti A, Marzotto M, Zanolini E. Effects of high dilutions in behavioural models: a commentary on critical 
issues from reproducibility to plausibility. Int J High Dilution Research 2011; 10(37):325-337

Bellavite P, Marzotto M, Olioso D, Moratti E, Conforti A. High-dilution effects revisited. 1. Physicochemical aspects. Homeopathy. 2014; 103(1):4-21

Bellavite P, Marzotto M, Olioso D, Moratti E, Conforti A. High-dilution effects revisited. 2. Pharmacodynamic mechanisms. Homeopathy. 2014; 103(1):22-43

Bellavite P, Signorini A, Marzotto M, Moratti E, Bonafini C, Olioso D. Cell sensitivity, non-linearity and inverse effects. Homeopathy. 2015, 104(2):139-160

Brizzi M, Elia V, Trebbi G, Nani D, Peruzzi M, Betti L. The efficacy of ultramolecular aqueous dilutions on a wheat germination model as a function of heat and aging-time. Evid Based Complement Alternat Med. 2011;2011:696298

Chatterjee BK. The mathematics of dilution. Homeopathy. 2014; 103(2):143-6

Czerlinski G, Ypma T. Domains of water molecules provide mechanisms of potentization in homeopathy. Water J 2010; 2:1-13

Chikramane PS, Kalita D, Suresh AK, Kane SG, Bellare JR. Why extreme dilutions reach non-zero asymptotes: a nanoparticulate hypothesis based on froth flotation. Langmuir. 2012; 28(45):15864-75

Chikramane PS, Suresh AK, Bellare JR, Kane SG. Extreme homeopathic dilutions retain starting materials: A nanoparticulate perspective. Homeopathy. 2010; 99(4):231-42

Chirumbolo S. Molecules and nanoparticles in extreme homeopathic dilutions: is Avogadro's Constant a dogma? Homeopathy. 2011 Jul;100(3):107-8

Chirumbolo S. Adverse effects and homeopathy: may remedies yet contain noxious or toxic molecules? Br J Clin Pharmacol. 2014; 78(1):184-5

Chirumbolo S. Homeopathy is not pharmacology. J Intern Med. 2013; 274(6):612-3

Csupor D, Boros K, Hohmann J. Low potency homeopathic remedies and allopathic herbal medicines: is there an overlap? PLoS One. 2013; 8(9):e74181

Demangeat JL. Gas nanobubbles and aqueous nanostructures: the crucial role of dynamization. Homeopathy. 2015; 104(2):101-15

Elia V, Napoli E, Germano R. The 'Memory of Water': an almost deciphered enigma. Dissipative structures in extremely dilute aqueous solutions. Homeopathy. 2007; 96(3):163-9

Elia V, Marchettini N, Napoli E, Niccoli M. Calorimetric, conduttimetric and density measurements of iteratively filtered water using 450 200, 100 and 25 nm Millipore filters J Therm Anal Calorimetry 2013; 114:927-936

Elia V, Napoli E, Niccoli M. Calorimetric and conduttometric titrations of nanostructures of water molecole in iteratively filtered water J Therm Anal Calorimetry 2013; 111:815-821

Elia V, Ausanio G, De Ninno A, Gentile F, Germano R, Napoli E. Experimental Evidence of Stable Aggregates of Water at Room Temperature and Normal Pressure After Iterative Contact with a Nafion ${ }^{\circ}$ Polymer Membrane. Water (AU) 2013; 5:16-26

Elia V, Lista L, Napoli E, Niccoli M. A thermodynamic characterization of aqueous nanostructures of water molecules formed by prolonged contact with the hydrophilic polymer Nafion. J Therm Anal Calorimetry 2014; 115:1841-1849

Elia V, Germano R, Napoli E. Permanent Dissipative Structures in Water: The Matrix of Life? Experimental Evidences and their Quantum Origin. Curr Top Med Chem. 2015; 15(6):559-71

Fisher P, Greenwood A, Huskisson EC, Turner P, Belon P. Effect of homeopathic treatment on fibrositis (primary fibromyalgia). BMJ. 1989 Aug 5;299(6695):365-6

Gurevich KG, Agutter PS, Wheatley DN. Stochastic description of the ligand-receptor interaction of biologically active substances at extremely low doses. Cell Signal. 2003; 15(4):447-53

Macías-Cortés Edel C, Aguilar-Faisal L, Asbun-Bojalil J. Efficacy of individualized homeopathic treatment and fluoxetine for moderate to severe depression in peri- and postmenopausal women (HOMDEP-MENOP): study protocol for a randomized, double-dummy, double-blind, placebo-controlled trial. Trials. 2013 Apr 23;14:105

Magnani P, Conforti A, Zanolin E, Marzotto M, Bellavite P. Dose-effect study of Gelsemium sempervirens in high dilutions on anxietyrelated responses in mice. Psychopharmacology (Berl). 2010; 210(4):533-45

Marzotto M, Olioso D, Brizzi M, Tononi P, Cristofoletti M, Bellavite P. Extreme sensitivity of gene expression in human SH-SY5Y neurocytes to ultra-low doses of Gelsemium sempervirens. BMC Complement Altern Med. 2014; 14:104

Milgrom LR. Is homeopathy possible? J R Soc Promot Health. 2006; 126(5):211-8

Olioso D, Marzotto M, Moratti E, Brizzi M, Bellavite P. Effects of Gelsemium sempervirens L. on pathway-focused gene expression profiling in neuronal cells. J Ethnopharmacol. 2014; 153(2):535-9

Peckham EJ, Nelson EA, Greenhalgh J, Cooper K, Roberts ER, Agrawal A.Homeopathy for treatment of irritable bowel syndrome. Cochrane Database Syst Rev.2013 Nov 13;11:CD009710

Pérol D, Provençal J, Hardy-Bessard AC, Coeffic D, Jacquin JP, Agostini C, Bachelot T, Guastalla JP, Pivot X, Martin JP, Bajard A, RayCoquard I. Can treatment with Cocculine improve the control of chemotherapy-induced emesis in early breast cancer patients? A randomized, multi-centered, double-blind, placebo-controlled Phase III trial. BMC Cancer. 2012 Dec 17;12:603

Roy R, Tiller WA, Bell I, Hoover MR. The structure of liquid water: novel insights from materials research, potential relevance for homeopathy Ind J Res Homeopathy, 2008; 3(2):1-24

Vallance AK. Can biological activity be maintained at ultra-high dilution? An overview of homeopathy, evidence, and Bayesian philosophy. J Altern Complement Med. 1998; 4(1):49-76

Ynnon TA, Elia V. Dynamics in perturbed very diluted aqueous solutions: theory and experimental evidence. Int J Modern Phys B, 2013 ; 1550005

Zanasi A, Mazzolini M, Tursi F, Morselli-Labate AM, Paccapelo A, Lecchi M. Homeopathic medicine for acute cough in upper respiratory tract infections and acute bronchitis: a randomized, double-blind, placebo-controlled trial. Pulm Pharmacol Ther. 2014 Feb;27(1):102-8

$$
\text { -- } 0 \text {-- }
$$

